Available online on 15.05.2020 at http://jddtonline.info
Open Access to Pharmaceutical and Medical Research
(c) 2011-18, publisher and licensee JDDT, This is an Open Access article which permits
unrestricted non-commercial use, provided the original work is properly cited

Open Access

Research Article

\title{
Fractionation, Phytochemical Screening and Free Radical Scavenging Capacity of Different Sub-Fractions from Pituranthos scoparius Roots
}

\author{
Ahlem Karbabi*, Kamel Mokhnache1, Lekhmici Arrar1, Abderahmane Baghiani1, Seddik Khennouf², \\ Noureddine Charef ${ }^{*} *$ \\ ${ }^{1}$ Laboratory of Applied Biochemistry, Department of Biochemistry, Faculty of Natural and Life Sciences, University Ferhat Abbas, Setif-1, 19000 \\ Algeria \\ ${ }^{2}$ Laboratory of Phytotherapy Applied to Chronic Diseases, Faculty of Natural and Life Sciences, University Ferhat Abbas, Setif-1, 19000 Algeria
}

\begin{abstract}
The purpose of this study was to prepare three sub-fractions from Pituranthos scoparius roots (PSR), characterize their phytochemicals contents and to investigate their free radical scavenging activity by 2,2'-azino-bis(3-ethylbenzothiazoline-6-sulfonic acid) (ABTS) and hydroxyl scavenging activities. Tannins, flavonoids, steroids, and other bioactive compounds were found in the different sub-fractions. The Ethyle acetate extract (EAE) and chloroform extract (ChE) exhibited the highest antioxidant activity using ABTS $(17.8 \pm 0.87 \mu \mathrm{g} / \mathrm{mL}$ and $18.15 \pm 0.68 \mu \mathrm{g} / \mathrm{mL})$, respectively. Whereas, Crude extract ( $\mathrm{CrE}$ ) have been presented strong hydroxyl scavenging activity $(14.9 \pm 0.8 \mu \mathrm{g} / \mathrm{mL})$. This study indicates that PSR extracts has potent free radical scavenging, and may prove to be of potential health benefit as well as additional resources for natural antioxidants.
\end{abstract}

Keywords: Medicinal plant; phytochemical screening; sub-fractions, free radical scavenging.

Article Info: Received 11 March 2020; Review Completed 23 April 2020; Accepted 29 April 2020; Available online 15 May 2020

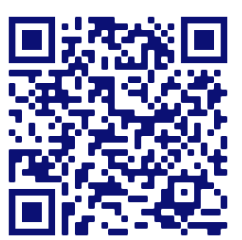

Cite this article as:

Karbab A, Mokhnache K, Arrar L, Baghiani A, Khennouf S, Charef N, Fractionation, Phytochemical Screening and Free Radical Scavenging Capacity of Different Sub-Fractions from Pituranthos scoparius Roots, Journal of Drug Delivery and Therapeutics. 2020; 10(3):133-136 http://dx.doi.org/10.22270/jddt.v10i3.4100

Ahlem Karbab \& Noureddine Charef, Laboratory of Applied Biochemistry, Department of Biochemistry, Faculty of Natural and Life Sciences, University Ferhat Abbas, Setif-1, 19000 Algeria.

\section{INTRODUCTION}

Antioxidants are substances that significantly delay or inhibit oxidation of an oxidizable substrate when present at low concentrations in comparison with those of the substrate 1. Nowadays, the scientists have casted some toxicological doubts on synthetic antioxidants due to their adverse faction effects, and people are more concerned about food safety and quality ${ }^{2}$.

Evidences showed that natural antioxidants deliver better effectiveness as compared to synthetic antioxidants. Natural products have always remained a profile source for the discovery of new drugs 3 .

In this context, the present research aims to investigate one of the medicinal plants used for various therapeutic purposes in Algerian folk medicine, which is Pituranthos scoparius, commonly known as "Guezzah" 4. This plant used for the treatment of asthma, measles, digestive disorders, jaundice and rheumatism. Preliminary phytochemical screening has indicated the presence of tannins, flavonoids, sterols and other phytochemical components in the roots 5 . However, few studies have investigated its free radical scavenging activities. Previous studies showed that the phytochemical analysis of ethyl acetate extract from $P$. scoparius roots revealed the isolation of two isocoumarins: $3-$ n-propyl-5-methoxy-6-hydroxy- isocoumarin and 3-npropyl-5,7-dimethoxy-6-hydroxy isocoumarin ${ }^{6}$. In addition, Benalia et al. 7 have shown a high in vitro anti-urolithiatic effect of $P$. scoparius roots extracts.

The current study was undertaken to evaluate the in vitro antioxidant potential of Algerian Pituranthos scoparius root extracts (PSRE) by ABTS radical scavenging and hydroxyl scavenging activity. In addition, phytochemical of different extracts were also measured, to establish any relationship between the antioxidant activities and these compounds.

\section{MATERIALS AND METHODS}

\section{Plant collection and identification}

The Roots of Pituranthos scoparius were collected from the mountain Djebel Zdimm located about twenty kilometers south of Setif (Algeria) at an altitude of $1212 \mathrm{~m}$ above sea level. The plant was identified by Pr H. Laouer (Laboratory of Valorization of Natural Biological Resources, University of 
Setif, Algeria) under voucher specimen (013/DBEV/UFA/18), then air-dried under shadow at room temperature to preserve their properties, then powdered and stocked in darkness until use.

\section{Bioactivity-guided fractionation}

The three sub-fractions of Pituranthos scoparius roots (PSR) were prepared according to ${ }^{8}$ method, using solvents with different polarities. Dried plant material was macerated in methanol/water 85/15 (v/v), in a vegetal material/solvent ratio $1: 10(\mathrm{w} / \mathrm{v})$ and the mixture was subjected to agitation during an overnight at $4^{\circ} \mathrm{C}$ with occasional shaking (Figure 1). All the solvents were eliminated by evaporation under reduced pressure.

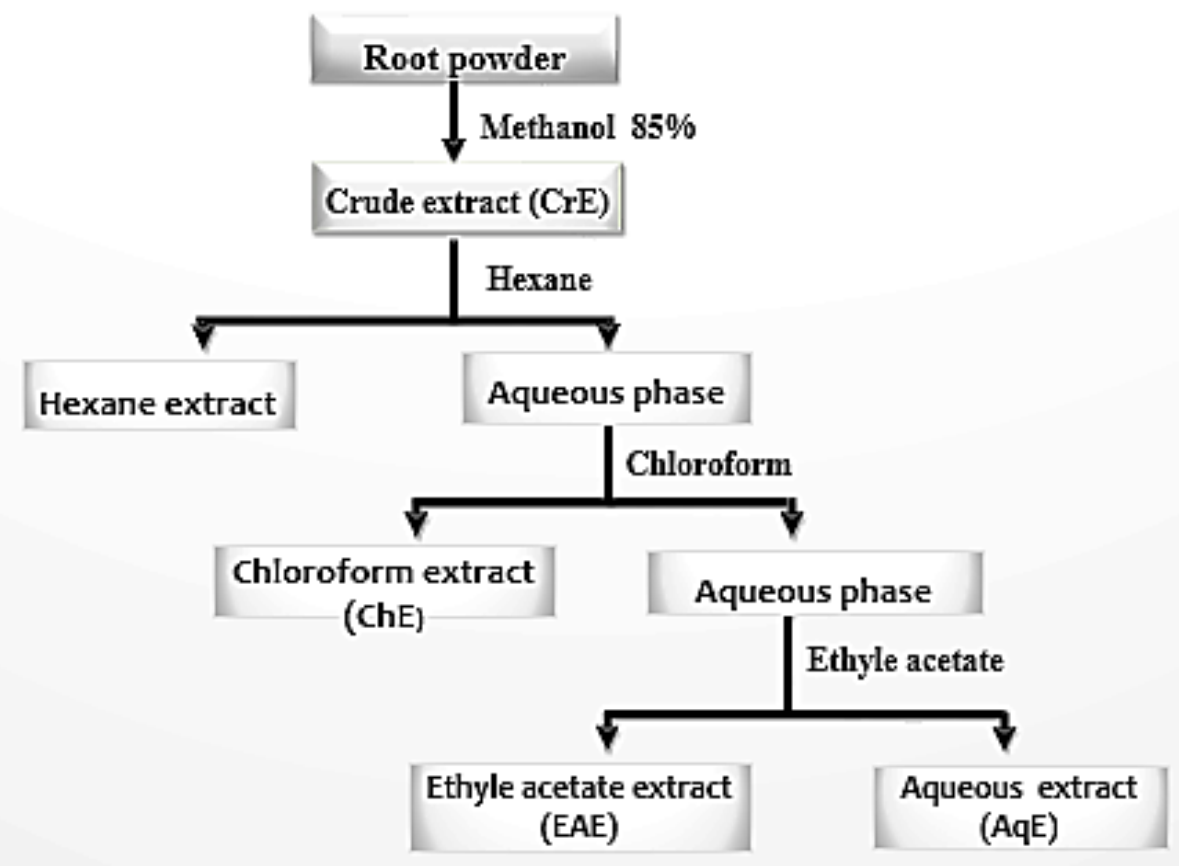

Figure 1: Steps for preparation of sub-fractions, where; crude extract (CrE), chloroform extract (ChE), ethyle acetate extract (EAE).

\section{Qualitative detection of phytochemical constituents}

Qualitative tests for the presence of different phytochemical compounds include: tannins, flavonoids, quinones, anthraquinones, saponins, steroids, glycosides, terpenoids and carbohydrates were carried out on the roots extracts using the procedures of 9 .

\section{Antioxidant capacity by ABTS radical assay}

The colorimetric analysis of ABTS ${ }^{+}$radical scavenging assay was determined according to 10 method with slight modifications. The $\mathrm{ABTS}^{+}$solution was formed by the reaction of $7 \mathrm{mM}$ of ABTS solution in $2.45 \mathrm{mM}$ potassium persulfate. The mixture was saved in the dark at room temperature for $16 \mathrm{~h}$ before use. The solution was diluted with absolute ethanol and equilibrated at room temperature to give an absorbance of 0.7 at $734 \mathrm{~nm}$. Then, $20 \mu \mathrm{L}$ of the extract dilutions was mixed with $2 \mathrm{~mL}$ of ABTS ${ }^{+}$solution and kept for six min at room temperature. The absorbance was measured at $734 \mathrm{~nm}$. The scavenging capability of ABTS+ radical was calculated according to the following formula :

$$
\mathrm{I} \%=\left(\mathrm{A}_{\text {blank }}-\mathrm{A}_{\text {test }} / \mathrm{A}_{\text {blank }}\right) \times 100 .
$$

Where Ablank is the absorbance of the solution except the test compound, and $A_{\text {test }}$ is the absorbance of the tested compound.

\section{Hydroxyl radical scavenging test}

The hydroxyl radical scavenging ability was estimated using the spectrometric method 11. Briefly, A mixture contained one $\mathrm{mL}$ of $\mathrm{FeSO}_{4}(1.5 \mathrm{mM}), 0.7 \mathrm{~mL}$ of $\mathrm{H}_{2} \mathrm{O}_{2}(6 \mathrm{mM})$ was mixed with varying concentrations of samples or ascorbic acid as a positive control. Then, $0.3 \mathrm{~mL}$ of sodium salicylate $(20 \mathrm{mM})$ was added, the resulting mixture was incubated at $37^{\circ} \mathrm{C}$ for 20 min. After that, the absorbance of the hydroxylated salicylate complex was measured at $562 \mathrm{~nm}$. The percentage scavenging effect was calculated as scavenging rate (Hydroxyl radical scavenging activity \% or I \%) by the following equation :

$$
I(\%)=\left[1-\left(A_{s}-A_{c}\right) / A_{0}\right] \times 100
$$

Where $A_{0}$ was the absorbance of the control (without sample) and $A_{s}$ was the absorbance in the presence of the sample, $A_{c}$ was the absorbance without sodium salicylate.

\section{Statistical analysis}

Statistical analysis was performed by using the Graph Pad Prism (version 5.03 for Windows). In this study, statistical analysis was analyzed by one-way analysis of ANOVA. All determinations were carried in triplicate, and all results were estimated as the mean \pm standard deviation (SD). Tests of significant differences were determined by multiple range tests at $\mathrm{p}<0.05$.

\section{RESULTS AND DISCUSSION}

\section{Phytochemical screening}

The phytochemical screening results of the PSR extracts are reported in table 1 . The roots were observed to contain tannins, flavonoids, free quinones, steroids, keto compounds were detected in all extracts. However, anthraquinones, glycosides, saponins, terpenoids, reducing sugars were not 
found in the all extracts. Phytochemical analyses carried out by 5,12 on the roots part of Pituranthos scoparius extracts revealed the presence of reducing sugars, flavonoids, tannins and steroids. Moreover, terpenoids are also present in almost all the studied extracts. These differences may be related to different conditions of extraction, time of collection...etc.

Table 1: Phytochemical screening of different P. scoparius roots extracts

\begin{tabular}{|c|c|c|c|}
\hline Phytochemical compounds & CrE & ChE & EAE \\
\hline Tannins & + & + & + \\
\hline Flavonoids & + & + & + \\
\hline Quinones & + & + & + \\
\hline Anthraquinones & - & - & - \\
\hline Glycosides & - & - & - \\
\hline Saponins & - & - & - \\
\hline Steroids & + & + & + \\
\hline Terpenoids & - & - & - \\
\hline Reducing sugars *Fehling's solution's & - & - & - \\
\hline *Seliwanoff's solution & + & + & + \\
\hline
\end{tabular}

\section{ABTS radical scavenging assay}

The free radical scavenging activity of PSRE was also determined using ABTS radical. The results revealed that all extracts scavenged the ABTS cations with $\mathrm{IC}_{50}$ values varying from 17.8 to $51.47 \mu \mathrm{g} / \mathrm{mL}$ (Figure 2). These values are close to that of Vit $\mathrm{C}$ with an $\mathrm{IC}_{50}$ value $0.075 \pm 0.001 \mu \mathrm{g} / \mathrm{mL}$. As seen in Figure 2, the highest ABTS radical scavenging activity was exhibited with EAE and $\mathrm{ChE}$ followed by $\mathrm{CrE}$ with $\mathrm{IC}_{50}$ values of $17.8 \pm 0.87 \mu \mathrm{g} / \mathrm{mL}, 18.15 \pm 0.68 \mu \mathrm{g} / \mathrm{mL}$ and $51.47 \pm$ $1.01 \mu \mathrm{g} / \mathrm{mL}$, respectively.

The high ABTS radical scavenging ability of EAE and ChE can be attributed to the presence of phenolic compounds. The earlier studies reported that ABTS radical scavenging capacity of bioactive compounds depends on their molecular weight, structure and presence of aromatic groups ${ }^{13}$.

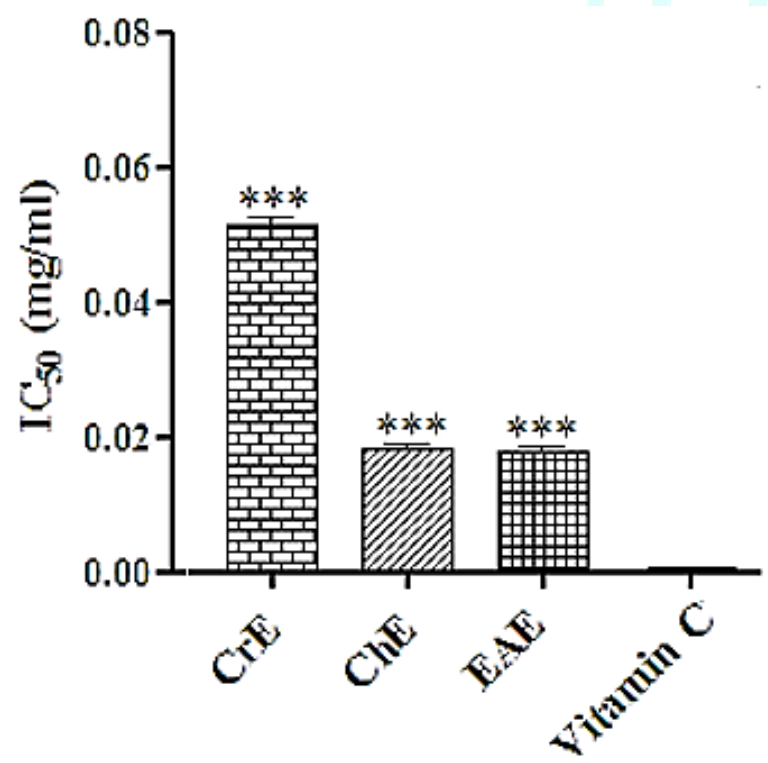

Figure 2: Free radical scavenging activity of different PSRE for ABTS assay. Data were presented as means $\pm \operatorname{SD}(n=3)$. ***: $P<0.001$ compared to Vitamin $\mathrm{C}$ as standard.

\section{Hydroxyl radical scavenging activity}

Hydroxyl radicals generated by the Fenton reaction could oxidize $\mathrm{Fe}^{2+}$ into $\mathrm{Fe}^{3+}$ which is reflected by the degree of decolorization of the reaction solution. In this assay, $\mathrm{OH}^{*}$ radicals were generated using a system containing $\mathrm{FeSO}_{4}$ and $\mathrm{H}_{2} \mathrm{O}_{2}$ and detected by their ability to hydroxylate salicylate. Vitamin $\mathrm{C}$ was used as a standard antioxidant for comparison $\left(\mathrm{IC}_{50}=83.6 \pm 1.4 \mu \mathrm{g} / \mathrm{mL}\right)$. The radical scavenging activity of PSRE decreased in the following order CrE $(14.9 \pm 0.8$ $\mu \mathrm{g} / \mathrm{mL}), \operatorname{ChE}(290.3 \pm 0.02 \mu \mathrm{g} / \mathrm{mL})$ and then EAE (458.4 \pm $0.61 \mu \mathrm{g} / \mathrm{mL}$ ). The results are summarized in Figure 3 .

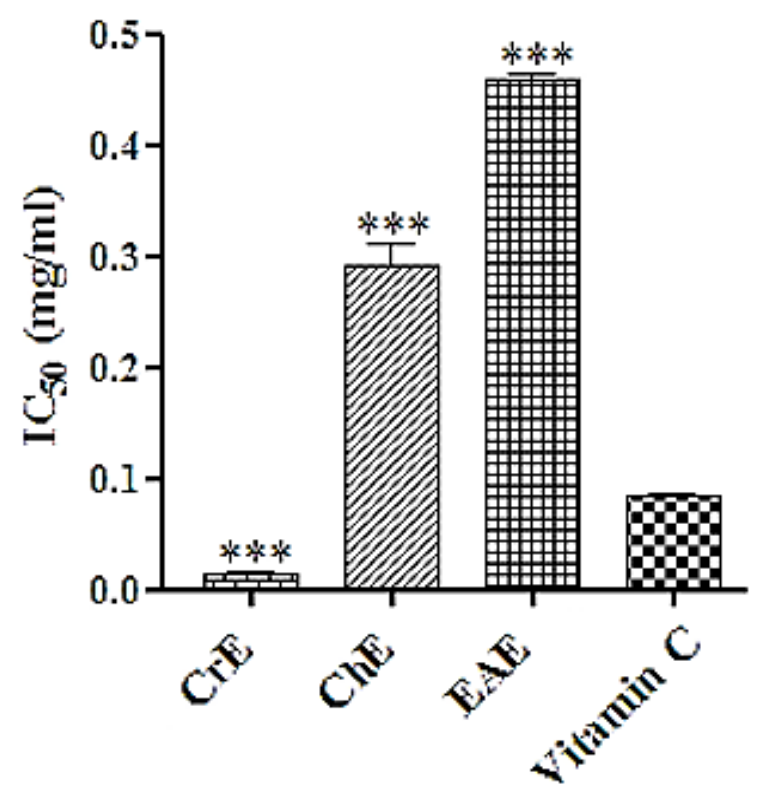

Figure 3: Hydroxyl radical scavenging activity of different $P$. scoparius L. extracts. Data were presented as means \pm SD ( $n=$ 3). ${ }^{* *}: P<0.001$ compared to standard.

Hydroxyl radical is a potent cytotoxic factor able to attack almost every molecule in the body resulting in peroxidation of cell membrane lipids and in the formation of malondialdehyde, which is mutagenic and carcinogenic 14 . Therefore, the scavenging of hydroxyl radical by extracts may provide significant protection to biomolecules by their ability to remove hydroxyl and superoxide free radicals due to inhibition of respective mechanisms involved in the formation of radicals 15 .

The higher potency of the scavenging hydroxyl radicals may be attributable to the presence of the hydrogen donating ability phenolic compounds in the extracts; which is highly related to the presence of hydroxyl groups ${ }^{16}$. Furthermore, the potent radical scavenging effects of the extracts may be related to the expanded steric obstacle 17 in compounds contained in these extracts.

\section{CONCLUSION}

The findings of the present study indicate that Pituranthos scoparius could be a new source of natural antioxidant drugs. The data highlights the good free radical scavenging properties of different extracts from Pituranthos scoparius roots. This antioxidant potential is probably associated with the presence of various secondary metabolites which may have many benefits in treating oxidative stress-related diseases. These results lay the preparation for further studies on the molecular mechanisms underlying the 
biological profile of these extracts, isolation and purification of more active principles in each extract as well as clarification of their mode of action. These in vitro results should be validated in vivo to develop a potent antioxidant agent from this plant.

\section{ACKNOWLEDGEMENTS}

This work was supported by the Algerian Ministry of Higher Education and Scientific Research (MESRS), this support is highly acknowledged. Authors would like also to thank Prof H. Laouer (Laboratory of Valorization of Natural Biological Resources, University of Sétif1, Algeria), for the identification of the plant material.

\section{REFERENCES}

[1]: Adebiyi O.E., Olayeni O., Ning-Hua T., Guang-Zhi Z. In vitro antioxidant activity, total phenolic and flavonoid contents of ethanol extract of stem and leaf of Grewia capinifolia. Beni-seuf uni.J.Appl. Sci, 2017; 6:10-14.

[2]: Yeşilyurt V., Halfon B., Öztürk M., Topçu G. Antioxidant potential and phenolic constituents of Salvia cedronella. Food Chem, 2008; 108:31-39.

[3]: Sandhar H.K., Kumar B., Prasher S., Tiwari P., Salhan M., Sharma P. A Review of Phytochemistry and Pharmacology of Flavonoids. I. P. S, 2011; 1:25-41.

[4]: Benmekhbi L., Kabouche A., Kabouche Z., Ait-Kaki B., Touzani R., Bruneau C. Five glycosylated flavonoids from the antibacterial butanolic extract of Pituranthos scoparius. Chem. Nat. Comp, 2008; 44:639-641.

[5]: Adida H., Benariba N., Bechiri A., Chekroun E., Djaziri R. Phytochemical study and evaluation of the antiradical activity of extracts of Pituranthos scoparius. Phytothérapie, 2015; 14:207212.

[6]: Haba H., Benkhaled M., Georges M., Christophe L., Catherine L. Alkylated isocoumarins from Pituranthos scoparius. Nat. Prod. Res, 2004; 18:409-413.

[7]: Benalia H., Djeridane A., Bensafieddine F., Yousfi M. High in vitro antiurolithiatic effect of Pituranthos scoparius roots extracts. Pharmacologyonline, 2016; 1:31-43.
[8]: Baghiani A., Djarmouni M., Boumerfeg S., Trabsa H., Charef N., Khennouf S., Arrar L.. Xanthine Oxidase Inhibition and Antioxidant Effects of Peaganum harmala Seed Extracts. European. J. Med. Plants, 2012; 2:42-56.

[9]: Musto M., Potenza G., Cellini F. Inhibition of Penicillium digitatum by a crude extract from Solanum nigrum leaves. Biotechnol. Agron. Soc. Environ, 2014; 18:174-180

[10]: Bouaziz A., khennouf S., Abu zarga M., Abdalla S., Baghiani A., Charef N. Phytochemical analysis, hypotensive effect and antioxidant properties of Myrtus communis L. growing in Algeria. Asian Pac J Trop Biomed, 2015; 5:19-28.

[11]: Ates B., Abraham L., Ercal N. Antioxidant and free radical scavenging properties of $\mathrm{N}$-acetylcysteine amide (NACA) and comparison with N-acetylcysteine (NAC). Free Radic. Res, 2008; 42:372-377.

[12]: Adida H., Frioui E., Djaziri R., Mezouar D. In vitro antibacterial activity of Pituranthos scoparius from Algeria. Int. J. Biol. Sci, 2014; 8:2095-2108.

[13]: Singh M., Pandey N., Agnihotri V., Singh K.K., Pandey A. Antioxidant, antimicrobial activity and bioactive compounds of Bergenia ciliate Sternb.: A valuable medicinal herb of Sikkim Himalaya. J. Tradit. Complement Med, 2017; 7:152-157.

[14]: Salar R.K., Sharma P., Purewal S. In vitro antioxidant and free radical scavenging activities of stem extract of Euphorbia trigona Miller. Association of Humanitas Medicine, 2015; 5:14.

[15]: Kumar V.K.S., Palaksha M.N., Venkatesh K., Kumar Y.S., Naik R.R. Antioxidant and hepatoprotective effects of methanolic extract of Origanum majorana in $\mathrm{CCl}_{4}$ induced liver injuryin rats. World J. Pharm. Pharm. Sci, 2013; 2:5898-5912.

[16]: Pavithra K., Vadivukkarasi S. Evaluation of free radical scavenging activity of various extracts of leaves from Kedrostis foetidissima (Jacq.). Cogn. Food Sci. and Human Wellness, 2015; $4: 42-46$.

[17]: Mokhnache K., Karbab A., Charef N., Arrar L., Mubarak M.S. Synthesis, characterization, superoxide anion scavenging evaluation, skin sensitization predictions, and DFT calculations for a new isonicotinylhydrazide analog. J. Mol. Struct. 2019; 1180:139-150 